$$
\begin{gathered}
\text { 영아 마사지가 교사-영아의 상호작용 및 } \\
\text { 어린이집 적응에 미치는 효과 } \\
\text { 이 미 나 } \\
\text { 목포대학교 아동학과 }
\end{gathered}
$$

\title{
The Effects of Infant Massage on Teacher-infant Interaction and Nursery Adaptation of Infants
}

Lee, Mi $\mathrm{Na}^{\dagger}$

Dept. of Children Education, Mokpo University, Mokpo, Kroea

\begin{abstract}
This research is to verify the effects of infant massage on teacher-infant interaction and nursery adaptation. The subjects were 20 infants younger than one year of age, and the experimental group and the control group were randomly assigned. I developed an infant massage activity and trained an infant teacher to do it with 30-hours workshop. The massage was accomplished a total of 18 times, 3 times a week for 6 weeks. The research tools employed are the Caregiver Interaction Scale(CIS) which was developed by Arnett(1989) and employed by Kim(2009) and the Preschool Adjustment Questionaire(PAQ) which was employed by Yang(2005). They were modified and supplemented for this study to serve as a teacher rating scale. The collected data was analyzed after the experiment service through the t-verification. The results showed that the experimental group that took the infant massage scored higher than the control group in both teacher-infant interaction and nursery adaptation. Therefore, it demonstrated that infant massage has an effect on positive and permissive interaction in teacher-infant interaction and nursery adaptation.
\end{abstract}

Key words: infant massage, teacher-infant interaction, nursery adaptation

\section{I. 서론}

영아기는 그들을 둘러싼 환경에 매우 민감하

며, 주변 환경에 지대한 영향을 받는다.

최근 여성의 사회 진출 및 핵가족의 확산 등
으로 인해 이르면 생후 3 개월부터 영아 보육기관 에서 대리양육을 경험하는 영아가 증가하는 추세 이다. 영아는 성인의 도움 없이는 생존할 수 없 으며, 선천적으로 주 양육자의 돌봄과 관심 없이 는 성장이 불가능한 존재이다. 이 시기 주 양육

접수일: 2013년 8월 13일 심사일: 2013년 9월 17일 게재확정일: 2013년 9월 27일

Corresponding Author: Lee, Mi Na Tel: 82-???

e-mail:1mn4780@naver.com

This is an Open-Access article distributed under the terms of the Creative Commons Attribution Non-Commercial License (http://creativecommons.org/licenses/by-nc/3.0) which permits unrestricted non-commercial use, distribution, and reproduction in any medium, provided the original work is properly cited. 
자가 얼마나 적절하고 신속하게 영아의 신호에 반응하는가에 따라 상당한 개인차가 나타나며, 이를 초기 애착연구자들은 주 양육자와 영아 애 착관계의 중요성을 강조하였으며, 특히 3 세 이전 애착형성의 시기에 어머니로 부터의 격리는 영아 의 정서 상태와 행동을 결정하는 주요 변인(Bowlby 1973)으로 영아의 정서적인 안정감을 저해하고 애 착발달에 문제를 가져오게 된다고 하였다.

인간은 출생 시부터 감각기능이 비교적 잘 발 달되어 있으며 촉각발달이 가장 두드러진다. 촉 각기관은 자궁 내에서 최초 발달하는 신경체계로 서 의사소통 방법 중 가장 오래 되고 기본적이며 적극적인 수단이다(Soo 2000). 촉각전달 신경은 임신 10 주가 되면 태아 피부에 나타나며 4 개월째 에는 촉각을 관장하는 뇌의 체지각 피질이 가동 되는데 이 때 임산부의 배를 부드럽게 마사지 하 면 태아의 움직임이 나타나기도 한다. 촉각자극 은 최적의 성장발달 및 주 양육자와 영유아 관계 형성에 기본이 되며 촉각자극을 통한 학습은 다 른 감각을 통한 연계 학습에 절대적으로 필요하 다고 하였다. 또한 촉각자극은 자신과 주위 환경 에 대한 인식력을 높여서 개인에게 의미 있는 감 각과 지각의 발달을 유도하며 다른 자극과 연계 를 촉진하는 기능을 한다(Field et al. 1996). 이런 신체접촉은 언어나 감정적 접촉 보다 그 정서적 효과가 10 배는 더 강하고 우리의 행동에 영향을 준다. 이처럼 촉각만큼 사람을 자극하는 감각은 없으며 우리는 그 사실을 알면서도 거기에 생물 학적 근거가 있다는 것을 깨닫지 못하는 경우가 많다(Schanberg \& Field 1987). 영국 과학 잡지 '네이처'에서는 '어머니의 따뜻한 손길이 자녀의 신경조직을 자극해 정서적 안정과 신체발육을 촉 진한다. 라고 보도하였고 우리나라 역시 예로부 터 전해져 내려온 '엄마 손은 약손'의 신비를 과 학으로 입증한 바 있다(Washington Post 2002).

어머니가 아이를 쓰다듬거나 연인이 서로 포 옹하는 등의 신체적 접촉을 통해 사랑의 감정이 뇌에 전달되는 신경조직이 인체에 있다는 것이 다. 학자들은 이 같은 신체접촉이 피부의 신경세 포를 따라 천천히 뇌 조직에 전해지면 특히 대뇌 의 사랑과 성적흥분을 느끼는 부위에 집중적으로
전달된다는 사실을 밝혀냈다. 인체에는 외부의 자극을 뇌신경에 전달하는 '굵은 신경세포(thick fiber)' 와 부드러운 신체 접촉 시 내분비 조직을 자극하는 '여린 신경세포(thin slow fiber)'가 있다. 손바닥처럼 외부의 자극을 많이 받는 신체부위는 상대적으로 굵은 신경세포가 발달한 데 비하여 팔 다리 같이 털이 많은 부위는 여린 신경세포가 발달한 부위다. 굵은 신경조직은 출생 후 서서히 발달하는데 비하여 부드러운 신체접촉을 전달하 는 여린 신경세포는 태아기 때부터 작용한다는 사실을 기존 연구에서 밝히고 있다. 이러한 연구 를 통해 학자들은 '어린 시기 부모와의 신체접촉 은 아이들의 정서안정은 물론 신체발달도 촉진시 킨다. 고 강조하고 있다.

영유아기 신체접촉은 건강한 정서발달에 도움 을 주고, 서로 간의 고통과 교감을 나누며, 감정 과 의사를 전달하면서 건강하고 안전한 관계를 형성하게 된다 $(\mathrm{Gu} 2002)$. 마사지를 하면서 눈 맞 춤, 피부접촉, 의사소통, 생리적 리듬 등의 여러 가지 요소를 어머니(교사)와 영아 간의 상호작용 에 통합시킨 구조적인 방법으로 신체접촉을 포함 한 마사지 자극은 영아의 성장 및 발달에 필요하 며 신체접촉은 영아에게도 위험하지 않은 안전한 과정(Morrow et al. 1991)이라 하였다.

영아 마사지란 근육을 자극하여 긴장을 완화 시키고 순환을 증가시켜 세포에의 영양공급을 증 진시키고, 조직과 근육의 혈액순환을 자극시킬 목적으로 피부를 두 손으로 부드럽게 마찰하는 것을 말한다(Choi \& Kim 2002). 이렇듯 교사와 영아의 정서적 유대감을 형성하는데 필요한 요소 로 사랑스러운 눈 맞춤, 따뜻한 손길, 다정스러운 음성을 비롯해 어머니(교사)에 대한 영아의 반응 및 스트레스, 호르몬 조절, 체온 조절, 면역체 형 성 등이 포함된다. 이 중에서도 눈 맞춤과 피부 접촉은 교사-영아간의 가장 호소력 있는 대화방 법 중 하나이므로 영아의 얼굴을 보면서 상호작 용을 하면 더 효과적이다. 즉 서로 눈 맞춤을 통 해 긍정적인 언어자극으로 “사랑해. ㅇㅇㅇㅑ" "아 이 예뻐라” 등의 말을 해주거나, 또 영아에게 노래를 불러줌으로 관계는 더 편안하게 된다. 또 마사지 할 때 어머니(교사)의 목소리는 영아의 
몸을 움직이게 하고, 높은 소리는 영아의 귀에 훨씬 더 감미롭게 들린다. 그러므로 노래를 부르 거나 이야기를 들려줄 수 있다. 영아는 마사지와 특정한 음성을 연상시키기도 하고 영아의 이름을 되풀이 해서 부른다거나 나직한 음성으로 "긴장 을 풀어” 라고 말해주면 영아는 이때부터 긴장을 해소하는 방법을 배울 수 있다(Lee 2012).

영아 마사지에서는 주로 접촉하기, 안아주기, 안고 흔들어 주기는 영아로 하여금 긴장을 풀어 주고 자신의 신체를 느끼게 한다. 또한 안고 흔 들기는 영아와 어머니(교사) 사이의 친밀감을 형 성하여 영아 양육에서 오는 무기력이나 화를 덜 느끼게 하므로 자폐아동과의 애착형성에 도움을 주었으며 마사지는 영아 뿐 아니라 마사지를 하 는 어머니(교사)에게 미치는 효과도 매우 크다 (Jeong 2000).

마사지 효과는 심리적, 신체적, 생리적 효과가 단독 또는 복합적으로 나타날 수 있다는 견해가 일반적이다. 즉 심리적인 효과로 기분상태 개선, 불안감소, 우울 및 스트레스 감소 효과가 있었으 며 생리적 반응 변수와도 관련되어 혈중 코티졸 농도를 감소시키고 면역물질을 증가시킨다(Field et al. 1996; Lee 2000). 또한, Field et al.(1996)은 경제적으로 어렵고 우울증을 가지고 있는 어머니 의 영아를 대상으로 마사지 실시 후 체중증가, 기질 향상, 스트레스 호르몬의 감소 등과 같은 긍정적인 결과가 나타났다. 또한 영아들은 정서 적, 사회적으로 안정되었고 수면양상이 현저히 향상되었다. 영아의 적응은 매우 중요하며, 이후 사회화 과정과 성공적인 집단생활을 위한 필수조 건이며, 영유아 보육기관에서 적응에 대한 이해 는 매우 의미 있는 과제라 할 수 있다. 영아는 보육시설에 입학함에 따라 새롭게 경험하게 되는 환경의 변화에 매우 큰 스트레스를 받는다. 영아 의 적응문제는 사회화 과정에 지속적인 영향을 미치며 성공적인 삶을 위해 어린이집 적응을 잘 할 수 있도록 돕는 중요한 요인이 된다(Perry \& Weinstein 1998; Fletcher et al. 2001). 적응은 환경 과의 관계에서 균형 있고 조화롭게 이루어지는 상호작용이고, 욕구좌절이나 갈등을 합리적이고 능동적으로 해결해 나가는 행동과정이라고 할 수
있다.

또한 영아는 사람과의 접촉 및 상호작용을 통 하여 세상을 알아가게 되고, 자신을 인식할 수 있게 된다(Jo 2006). 1세가 되면 영아의 사회적 반응은 더욱 분명히 나타나 좋아하는 사람과 좋 아하지 않는 사람의 구분이 명확해지고, 주 양육 자와의 관계도 더 깊어져 양육자 외 타인과의 접 촉, 관계에 매우 민감하게 반응한다(Gwak 2005). 영아가 낮선 환경에서 부모와 격리되는 경험을 하면서 적응하기 까지 많은 내적, 외적 갈등과 변화과정을 거친다. 이처럼 적응이란 개인이 환 경에 순응하는 것이 아니라 환경과의 관계에서 조화롭고 균형 있게 이루어지는 상호작용이며, 옥구좌절이나 갈등을 능동적이고 합리적으로 해 결해 나가는 행동과정이다(Song 2007). 이에 본 연구에서는 영아에게 접촉이라는 마사지를 활용 하여 교사와 정서적으로 친밀감을 형성하고 어린 나이에 분리 될 수밖에 없는 현실에 보다 어린이 집 기관에 적응을 잘 할 수 있도록 마사지를 실 시하여 그 효과를 보고자 하였다.

본 연구의 목적에 따라 연구문제를 설정하면 다음과 같다.

<연구문제 1> 영아마사지는 교사-영아의 상호 작용에 효과가 있는가?

<연구문제 2> 영아마사지는 영아의 어린이집 적응에 효과가 있는가?

\section{II. 연구방법}

\section{1. 연구 대상}

본 연구는 $\mathrm{G}$ 시에 소재한 $\mathrm{M}$ 어린이집과 $\mathrm{K}$ 어린 이집에 재원중인 만 0,1 세 영아 20 명(집단별 각 10 명)을 대상으로 각 어린이집 영아 중 입학 초 기 상호작용 및 적응이 어려운 영아를 대상으로 선정하고 실험집단과 통제집단을 무선으로 배정 하였다. 연구대상의 평균월령은 실험집단 17.24 (3.22)개월, 통제집단 19.35(3.47)개월로 집단 간의 통계적으로 두 집단은 동질 집단임을 나타냈다. 두 집단의 연구 대상 영아의 월령은 Table 1 에 제시된 바와 같다. 
Table 1. Homogeneity test of general characteristics between experimental and control group

\begin{tabular}{|c|c|c|c|c|c|c|c|c|}
\hline & \multicolumn{2}{|c|}{ Years } & \multicolumn{2}{|c|}{ Sex } & \multicolumn{2}{|c|}{ Month } & \multirow{2}{*}{$\mathrm{t}$} & \multirow{2}{*}{$\mathrm{p}$} \\
\hline & 0 & 1 & Male & Female & M & $\mathrm{SD}$ & & \\
\hline Experimental group $(n=10)$ & 3 & 7 & 7 & 3 & 17.24 & 3.22 & \multirow{2}{*}{.336} & \multirow{2}{*}{.618} \\
\hline Control group $(n=10)$ & 2 & 8 & 6 & 4 & 19.35 & 3.47 & & \\
\hline
\end{tabular}

Table 2. Homogeneity test of dependent variables between experimental and control group

\begin{tabular}{llllcc}
\hline \multicolumn{1}{c}{ Factor } & \multicolumn{1}{c}{ Group } & $\mathrm{N}$ & $\mathrm{M}$ & $\mathrm{SD}$ & $\mathrm{t}$ \\
\hline Teacher- & Experimental group & 10 & 73.07 & 15.93 & .920 \\
Infant interaction & Control group & 10 & 75.76 & 11.45 & 6.11 \\
\hline \multirow{2}{*}{ Nursery adaptation } & Experimental group & 10 & 39.17 & 6.54 & .566 \\
& Control group & 10 & 38.07 & & \\
\hline
\end{tabular}

각 집단별 교사-영아 상호작용, 어린이집 적응 에 대한 사전검사 결과는 다음의 Table 2와 같다.

각 집단별 사전점수 분석 결과 교사-영사 상호 작용에 대한 사전검사 점수는 실험집단 $(M=73.07$, $S D=15.93)$ 과 통제집단 $(M=75.76, S D=11.45)$ 간에 통 계적으로 유의한 차이가 나타나지 않았다 $(t=.920$, $p>.05)$. 또한, 어린이집 적응에 대한 사전검사 점 수는 실험집단 $(M=39.17, S D=6.11)$ 과 통제집단 $(M=38.07, S D=6.54)$ 간에 통계적으로 유의한 차이 가 나타나지 않았다( $t=.566, p>.05)$. 즉, 실험집단 과 통제집단이 동질 집단임을 알 수 있었다.

\section{2. 연구도구}

\section{1) 영아마사지}

영아마사지는 국제전문지도자협회에서 인정하 는 전문가가 실험집단 담당교사에게 영아마사지 방법에 대한 교육을 실시한 후 보육기관 및 부모 의 동의를 얻어 마사지를 실시하였다. 영아교사 교육시간은 영아 마사지 활용법 30시간 워크숍을 통해 교육한 후 실험집단 영아에게 총 6주 동안 주 3 회, 총 18 회기를 실시하였다. 마사지 교육은 (주)프로리더의 영아마사지 교사교육과정 기준에 맞춰 영아 마사지 활용법에 따라 회기를 구성하 였다. 본 연구 실험집단에게 사용한 영아 마사지
활동은 촉각 자극으로 이루어져 있으며, 소요 시 간은 약 15 분 정도이며, 배마사지, 가슴마사지, 얼굴마사지, 팔(손)마사지, 다리(발)마사지, 등마 사지 등으로 구성되었다. 영아마사지 활동은 오 전 목욕 후 11 시정도 18 회기 실시하였다.

2) 교사-영아 상호작용

교사-영아 상호작용 반응을 측정하기 위해 Arnett(1989)가 개발한 영아교사 상호작용 척도 (Caregiver Interaction Scale; CIS)를 Jo(2004)이 번 안하고 $\operatorname{Kim}(2009)$ 이 사용한 도구를 본 연구에 맞 게 수정 보완하여 사용하였다. 교사-영아 상호작 용 척도는 교사평정척도로 총 26 문항으로 5 점 척 도로 구성되어 있다. 하위요인으로 긍정적 상호 작용(positive interaction) 10 문항, 비판적 상호작용 (punitive interaction) 8 문항, 분리된 상호작용 (detached interaction) 4문항, 허용적 상호작용 (permissive interaction) 4 문항의 범주로 측정하도 록 되어 있다. Cronbach's $\alpha$ 는 긍정적 상호작용 문항이 $\alpha=.88$ 이고 비판적 상호작용문항은 $\alpha=.94$, 분리된 상호작용 문항이 $\alpha=.90$, 허용적 상호작용 문항이 $\alpha=.79$ 으로 나타났고, 전체는 Cronbach's $\alpha$ $=.81$ 로 나타났다.

\section{3) 어린이집 적응}

영아의 어린이집 적응 정도를 측정하기 위해 Jewsuwan et al.(1993)이 개발한 영아용 적응 질문 
Table 3. The contents of teacher-education

\begin{tabular}{ccc}
\hline Area & Session & Experimental group teacher-education content \\
\hline Massage & 1 & The meaning of infant massage \\
understanding & 2 & The effect of infant massage \\
& 3 & Infant massage and interactions \\
& 5 & Infant massage environment \\
Development & 6 & Infant massage environment \\
understanding & 7 & Dealing with a child's body and physical development \\
& 8 & The understanding of infant mentality \\
Massage & 9 & Infant massage - foot \\
application & 10 & Infant massage - legs \\
& 11 & Infant massage - hand \\
& 12 & Infant massage - arms \\
& 13 & Infant massage - face \\
& 14 & Infant massage - back \\
Massage & 15 & Infant massage - stomach \\
technique & 16 & Infant massage - chest \\
& 17 & Infant massage- digestive system \\
& 18 & Infant massage-circulatory system \\
\hline
\end{tabular}

지 PAQ(The Preschool Adjustment Questionaire)를 $\mathrm{Oh}(2001)$ 이 번안하고, $\mathrm{Yang}(2010)$ 이 사용한 것을 본 연구에 맞게 13 개월-24개월 영아에게 적합하 게 수정 보완하여 교사 평정 척도로 총 30 문항, 5점 척도로 구성되어 있다. 하위요인으로 친사회 적 행동 4 문항, 긍정적 감정 7 문항, 또래관계 6 문 항, 자아강도 4 문항, 일과 적응 9문항으로 구성되 었으며, Cronbach's $\alpha$ 는 친사회적 행동 $\alpha=.69$, 긍 정적 감정 $\alpha=.70$, 또래관계 $\alpha=.75$, 자아강도 $\alpha=$ .81 , 일과 적응 $\alpha=.77$, 전체 Cronbach's $\alpha=.88$ 이 다.

\section{3. 연구절차}

본 연구는 2012년 3월 26일부터 4월 30일까지 6 주에 걸쳐 실시하였다. 예비검사, 사전검사, 실 험처치, 사후검사의 순으로 진행하였다.

\section{1) 예비 검사 및 교사 훈련}

본 연구를 실시하기 전에 먼저 실험절차와 실 험 도구의 적절성 등을 알아보기 위한 예비 검사
를 3 일에 걸쳐 실시하였다. 실험에 참여하지 않 는 만 0,1 세 영아 5 명을 대상으로 영아 마사지 활동을 2 회 실시한 결과 신체적, 정서적 측면에 서 교사와 영아 모두 흥미롭게 이루어지는 활동 임을 알 수 있었다. 실험에 참여한 교사 훈련은 교사-영아 상호작용 측정 도구와 적응 측정 도구 에 대해 평가방법을 설명하고 충분히 숙지하도록 하였다. 또한 실험집단 만 0,1 세 영아 교사에게 3 일에 걸쳐 영아 마사지 활용법 대하여 18 회기 교 사교육을 실시하였다. 통제집단 만 0,1 교사에게 는 영아 보육과정에 맞춰 교사-영아 상호작용 수 업을 진행하도록 통제하였고, 일상적인 하루일과 를 보내도록 하였다.

\section{2) 사전검사}

사전검사는 2012년 3월 20일 3월 22일까지 실 시하였다. 교사-영아 상호작용 검사 도구와 어린 이집 적응 검사 도구를 담당교사가 영아를 주의 깊게 관찰하면서 체크하도록 하였다. 
3) 실험처치

\section{(1) 실험기간}

실험집단 대상영아에게 교사-영아 상호작용 검사도구와 어린이집 적응 검사도구의 변화과정 을 알아보기 위해 영아 마사지 활동은 2012년 3 월 26 일에서 4 월 30 일까지 약 15 분씩 주 3 회로 6 주 동안 총 18 회를 (주)프로리더 베이비 마사지 전문가협회에서 제시한 영아 마사지 주별 활동 횟수에 근거하여 실험처치 하였다.

(2) 실험 처치 내용

실험집단에게 영아 마사지는 오전 목욕 후 약 15 분정도 진행되었으며 영아교사 마사지 교육내 용과 영아마사지의 세부 내용은 Table 3 과 Table 4 와 같다. 영아 마사지 활동은 영아 신체적, 발달 적 특성에 맞게 설정하였으며 참고자료는 (주)프 로리더(International Pro-leader Association 2011)에
서 제공하는 베이비마사지 교재를 참고로 활동안 을 계획하였다.

\section{4. 사후검사}

본 연구의 실험 처치의 효과를 검증하기 위한 사후검사는 실험처치가 끝난 후 2012년 5월 2일 - 5월 3일 까지 사전검사와 동일한 방법으로 교 사-영아의 상호작용 검사 도구와 어린이집 적응 검사 도구를 담당 영아교사가 평정하도록 하였다.

\section{5. 자료분석}

본 연구에서는 영아 마사지 활동이 교사-영아 의 상호작용과 어린이집 적응에 영향을 알아보기 위해 집단 간 사전, 사후 검사의 점수를 SPSS 18.0 프로그램을 사용하여 $t$ 검증으로 비교·분석하 였다.

Table 4. The contents of Infant massage protocol

\begin{tabular}{|c|c|c|}
\hline Area & Session & Experimental group Infant massage content \\
\hline \multirow{4}{*}{ Foot, legs massage } & 1 & Infant massage - foot 1 \\
\hline & 2 & Infant massage - foot 2 \\
\hline & 3 & Infant massage - legs 1 \\
\hline & 4 & Infant massage - legs 2 \\
\hline \multirow{4}{*}{ Hand, arms massage } & 5 & Infant massage - hand 1 \\
\hline & 6 & Infant massage - hand 2 \\
\hline & 7 & Infant massage - arms 1 \\
\hline & 8 & Infant massage - arms 2 \\
\hline \multirow{4}{*}{ Face, back massage } & 9 & Infant massage - face 1 \\
\hline & 10 & Infant massage - face 2 \\
\hline & 11 & Infant massage - back 1 \\
\hline & 12 & Infant massage - back 2 \\
\hline \multirow{3}{*}{ Stomach, chest massage } & 13 & Infant massage - stomach 1 \\
\hline & 14 & Infant massage - stomach 2 \\
\hline & 15 & Infant massage - chest \\
\hline \multirow{3}{*}{ Oriental massage } & 16 & Infant massage- digestive system \\
\hline & 17 & Infant massage- circulatory system \\
\hline & 18 & Infant massage- respiratory \\
\hline
\end{tabular}




\section{III. 결과 및 고찰}

\section{1. 영아 마사지는 교사-영아의 상호작용에} 효과는 어떠한가?

영아 마사지가 교사-영아 간 상호작용 효과를 알아보기 위해 실험집단과 통제집단의 사전검사 와 사후검사 점수를 비교하여 제시하면 Table 5 와 같다.

Table 5에서와 같이 교사-영아 상호작용 사전 검사 점수에서는 실험집단 $(\mathrm{M}=93.07, \mathrm{SD}=15.93)$ 과 통제집단 $(\mathrm{M}=102.96, \quad \mathrm{SD}=11.45)$ 간에 통계적으로 유의한 차이가 나타나지 않았다( $\mathrm{t}=.920, \mathrm{p}>.05)$. 그러나 실험처치 후 집단 간 사후검사 결과 실험 집단 $(\mathrm{M}=119.58, \mathrm{SD}=13.51)$ 과 통제집단 $(\mathrm{M}=102.95$, $\mathrm{SD}=10.11)$ 간에 통계적으로 유의하게 높은 것으로 나타났다 $(\mathrm{t}=3.705, \mathrm{p}<.05)$. 이러한 결과는 영아 마 사지가 교사-영아 상호작용에 효과적임을 시사하 는 결과로 볼 수 있다.

영아 마사지가 교사-영아 상호작용의 하위영 역에 미치는 효과를 분석한 결과, 긍정적 상호작 용 $(\mathrm{t}=4.347, \quad \mathrm{p}<.01), \quad$ 허용적 상호작용 $(\mathrm{t}=3.263$, $\mathrm{p}<.01)$ 에서 실험집단 점수가 통제집단 점수보다 통계적으로 유의하게 높은 것으로 나타났다. 이 러한 연구결과는 영아 마사지가 긍정적 상호작 용, 허용적 상호작용에서 유의하게 효과가 있는 것으로 해석 할 수 있다.
2. 영아 마사지가 영아의 어린이집 적응에 효과는 어떠한가?

영아 마사지가 영아의 어린이집 적응에 효과 가 있는지 알아보기 위해 실험집단과 통제집단의 사전검사와 사후검사 점수를 비교하여 제시하면 다음 Table 6과 같다.

Table 6에서와 같이 어린이집 적응 사전검사 점수에서는 실험집단 $(\mathrm{M}=26.61, \mathrm{SD}=3.43)$ 과 통제 집단 $(\mathrm{M}=26.29, \mathrm{SD}=4.47)$ 간에 통계적으로 유의한 차이가 나타나지 않았다 $(\mathrm{t}=.767, \mathrm{p}>.05)$. 그러나 실험처치 후 집단 간 사후검사 결과점수는 실험 집단 $(\mathrm{M}=29.21, \quad \mathrm{SD}=4.27)$ 이 통제집단 $(\mathrm{M}=25.69$, $\mathrm{SD}=2.65)$ 보다 통계적으로 유의하게 높은 것으로 나타났다 $(\mathrm{t}=2.384, \mathrm{p}<.01)$. 이러한 결과는 영아 마 사지가 영아의 어린이집 적응에 효과적임을 시사 하는 결과로 볼 수 있다.

영아 마사지가 영아의 어린이집 적응 하위영 역에 미치는 효과를 분석한 결과, 친사회적 행동 $(\mathrm{t}=2.145, \mathrm{p}<.05)$, 긍정적 감정 $(\mathrm{t}=1.524, \mathrm{p}<.01)$, 또 래 관계 $(\mathrm{t}=1.845, \mathrm{p}<.05)$, 자아 강도 $(\mathrm{t}=2.415$, $p<.05)$, 일과 적응 $\left(\mathrm{t}=1.504^{*}, p<.05\right)$ 에서 실험집단 점수가 통제집단 점수보다 통계적으로 유의하게 높은 것으로 나타났다. 이러한 연구결과는 영아 의 마사지 활동이 어린이집 적응 영역에서 유의 하게 효과가 있는 것으로 해석 할 수 있다.

Table 5. Effects of infant massage on teacher-infant interaction between experimental and control group $(\mathrm{N}=10)$

\begin{tabular}{llccccc}
\hline & \multirow{2}{*}{ Sub-areas } & \multicolumn{2}{c}{ Experimental group } & \multicolumn{2}{c}{ Control group } & \multirow{2}{*}{$\mathrm{t}$} \\
\cline { 3 - 6 } & & $\mathrm{M}$ & $\mathrm{SD}$ & $\mathrm{M}$ & $\mathrm{SD}$ & \\
\hline \multirow{2}{*}{ Positive interaction } & A preliminary inspection & 31.93 & 5.60 & 33.31 & 4.37 & .716 \\
& A post inspection & 38.20 & 4.41 & 32.00 & 2.83 & $4.347^{* *}$ \\
\hline \multirow{2}{*}{ Punitive interaction } & A preliminary inspection & 28.20 & 6.96 & 32.54 & 3.86 & 1.993 \\
& A post inspection & 29.53 & 6.17 & 29.31 & 3.57 & 1.275 \\
\hline \multirow{2}{*}{ Detached interaction } & A preliminary inspection & 30.00 & 4.49 & 29.38 & 6.04 & 1.309 \\
& A post inspection & 31.07 & 5.16 & 29.23 & 6.97 & 1.101 \\
\hline \multirow{2}{*}{ Permissive interaction } & A preliminary inspection & 31.73 & 6.93 & 30.92 & 5.60 & .336 \\
& A post inspection & 39.13 & 3.68 & 32.46 & 6.11 & $3.263^{* *}$ \\
\hline \multirow{2}{*}{ Total } & A preliminary inspection & 93.07 & 15.93 & 102.96 & 11.45 & .920 \\
& A post inspection & 119.58 & 13.51 & 102.95 & 10.11 & $3.705^{*}$ \\
\hline
\end{tabular}

$* \mathrm{p}<.05, * * \mathrm{p}<.01$ 
Table 6. Effects of infant massage on nursery adaptation between experimental and control group $(\mathrm{N}=10)$

\begin{tabular}{|c|c|c|c|c|c|c|}
\hline & \multirow{2}{*}{ Sub-areas } & \multicolumn{2}{|c|}{ Experimental group } & \multicolumn{2}{|c|}{ Control group } & \multirow{2}{*}{$\mathrm{t}$} \\
\hline & & M & $\mathrm{SD}$ & M & $\mathrm{SD}$ & \\
\hline \multirow{2}{*}{ Prosocial behavior } & A preliminary inspection & 21.43 & 2.10 & 22.70 & 2.78 & 1.384 \\
\hline & A post inspection & 28.74 & 2.58 & 24.37 & 1.84 & $2.145^{*}$ \\
\hline \multirow{2}{*}{ Positive emotion } & A preliminary inspection & 21.70 & 4.73 & 23.92 & 3.16 & .149 \\
\hline & A post inspection & 25.07 & 5.72 & 25.96 & 6.46 & $1.524 * *$ \\
\hline \multirow{2}{*}{ Peer relationship } & A preliminary inspection & 21.43 & 3.10 & 27.80 & 2.78 & .938 \\
\hline & A post inspection & 28.74 & 2.58 & 25.37 & 1.84 & $1.845^{*}$ \\
\hline \multirow{2}{*}{ Ego stength } & A preliminary inspection & 24.43 & 3.10 & 29.70 & 2.78 & 1.384 \\
\hline & A post inspection & 27.74 & 2.18 & 27.57 & 1.84 & $2.415^{*}$ \\
\hline \multirow{2}{*}{ Daily work adaptation } & A preliminary inspection & 22.07 & 5.72 & 20.96 & 2.46 & .894 \\
\hline & A post inspection & 28.07 & 7.72 & 23.96 & 3.46 & $1.504 *$ \\
\hline \multirow{2}{*}{ Total } & A preliminary inspection & 26.61 & 3.43 & 26.29 & 4.47 & .767 \\
\hline & A post inspection & 29.21 & 4.27 & 25.69 & 2.65 & $2.384 * *$ \\
\hline
\end{tabular}

$* \mathrm{p}<.05, * * \mathrm{p}<.01$

\section{IV. 요약 및 결론}

본 연구는 영아마사지가 교사-영아의 상호작 용 및 어린이집 적응에 효과가 있는지를 알아보 고자 실시하였다. 연구의 결론은 다음과 같다.

영아 마사지 활동은 교사-영아의 상호작용 중 긍정적 상호작용, 허용적 상호작용에 의미 있는 효과가 있는 것으로 나타났으며, 또한 적응 전체 에서 의미 있는 효과가 있는 것으로 나타났다. 이는 영아 마사지 활동을 통해 실험집단 영아들 이 보여주는 의미 있는 변화는 영아 마사지 활동 이 교사-영아의 상호작용 및 어린이집 적응에서 의미 있는 활동임을 알 수 있다.

연구 문제별로 살펴보면 첫째, 영아마사지 활 동이 교사-영아의 상호작용 중 긍정적 상호작용 과 허용적 상호작용에 영향을 미치는 것으로 나 타났다. 즉, 영아 마사지 활동이 교사-영아의 상 호작용을 향상시키는 데 효과적이었으며, 영아기 신체접촉은 언어나 감정적 접촉에 비해 그 정서 적 효과가 10 배는 더 강하고 모든 행동에 영향을 준다는 결과와 촉각만큼 사람을 자극하는 감각은 없으며 그 사실을 알면서도 거기에 생물학적 근 거가 있다는 것을 깨닫지 못하는 경우가 많다고 한 Schanberg(1987)의 연구와 영아 마사지는 접촉
하기, 안아주기, 안고 흔들기는 영아로 하여금 긴 장을 풀어 주고 자신의 신체를 느끼게 한다. 마 사지는 영아 뿐 아니라 마사지를 하는 어머니(교 사)에게 미치는 효과도 매우 크며, 영아와 신체 적인 접촉을 통해 의사소통 할 수 있는 계기가 되며 이는 서로가 이해의 폭을 넓히는 수단으로 마사지를 활용 할 수 있다는 $\operatorname{Kim}(2009)$ 의 연구를 지지한다고 할 수 있다. 또한 교사-영아 관계에 서 교사와 온정적인 관계라고 지각한 영아는 적 응을 더 잘한다는 $\mathrm{An}(2001)$ 연구와 그 맥을 같이 한다고 할 수 있다.

둘째, 영아 마사지 활동은 어린이집 적응에 긍 정적인 영향을 미치는 것으로 나타났다. 즉, 영아 마사지 활동은 어린이집 적응의 하위영역인 친사 회적 행동, 긍정적 감정, 또래 관계, 자아 강도, 일과 적응에서 효과적인 영향을 미치는 것으로 나타났다. 즉, 영아 마사지 활동이 어린이집 적응 에 효과적이었다. 이는 어린이집에서 적응은 영 아가 자신의 고유한 특성과 요구를 가지고 새로 운 환경에 자신을 잘 맞추어 갈 뿐만 아니라 일 과에 능동적으로 참여하는 것을 말한다. 그리고 어린이집 내에서 영아와 또래 사이에서 불균형과 불안정 등의 긴장감 없이 조화와 균형이 잘 유지 되고, 새로이 속하게 된 집단의 규칙과 기대를 
따르며 새로운 환경과 조화를 이루어 행동을 변 화시켜 나가는 것을 의미한다는 $\mathrm{Kim} \& \mathrm{Shin}$ (2001)연구와 $\operatorname{Kim}(2003), \operatorname{Kim}(2004), \operatorname{Dan}(2004)$ 연 구와 그 맥을 같이 한다고 할 수 있다. 또한, 적 응을 잘 한다는 것은 영아 개인이 환경에 순응하 는 것이 아니라 환경과의 관계에서 조화롭고 균 형 있게 이루어지는 상호작용이며, 욕구좌절이나 갈등을 능동적이고 합리적으로 해결해 나가는 행 동과정이라는 Song(2007)의 연구를 일부 지지한 다고 할 수 있다. 즉 영아는 사람과의 접촉과 상 호작용을 통하여 세상을 알아가게 되고, 자신을 인식하고 사회를 인식하면서 점차 성장함에 따라 사회 속에서의 규칙, 방법, 기술 등을 터득해 나 가게 된다는 연구와 이러한 과정 속에서 영아는 사회적 존재로 살아가게 된다는 Kim et al.(2001) 연구와 $\mathrm{Jo}(2006)$ 연구를 지지한다고 할 수 있다. 또한, 영아기 신체접촉은 건강한 정서발달에 영 향을 주고, 서로 간의 고통과 교감을 나누며, 감 정과 의사를 전달하면서 정상적인 관계를 형성하 게 된다는 $\mathrm{Gu}(2002)$ 의 연구와 어머니(교사)와 영 아의 신체적 접촉을 증가시키는 가장 효과적인 방법으로 마사지 활동을 강조하고 있으며, 마사 지를 행하는 것은 눈 맞춤, 피부접촉, 의사소통, 생리적 리듬 등의 여러 가지 요소를 어머니(교 사)와 영아의 상호작용에 통합시킨 구조적인 방 법이라는 Lee(2012)의 연구와 일치한다고 할 수 있다.

영아 마사지 과정에서 나타난 실험집단은 신 체접촉을 통해 눈 맞춤과 영아의 신호에 대한 교 사의 더 민감한 반응을 보였으며 통제집단에 비 해 더 빈번한 상호작용을 하므로 통제집단 영아 들은 보다 안정되고 편안한 어린이집 생활을 하 는 것으로 관찰되었다.

본 연구의 결론을 토대로 제언을 하면, 첫째, 본 연구는 영아를 대상으로 실시된 연구이다. 본 연구의 근거에 따라 좀 더 장기간 실시하여 효과 를 검증해 볼 필요가 있다. 둘째, 본 연구에서 밝 혀진 영아 마사지 활동 결과를 토대로 불안정 애 착을 보이는 영아와 까다로운 기질의 영아 등 다 양한 접근으로 개발될 필요가 있다.

\section{References}

An SH(2001) Seoul, on the operation of full-day public kindergarten needs of mother and teacher surveys. Ewha Woman University Graduate School of Education Master's Thesis

Arnett J(1989) Caregivers in day care centres: Does training matter. J Appl Develop Psychol 10, 541552

Bowlby J(1973). Attachment and loss. Vol. 2. Seperation. Intern J Psycho-analysis 39, 350-373

Choi SY, Kim YH(2002) The effect of infant massage on mother-infant play interaction, J Korean Soc Nurs Sci 32(6), 823-831

Dan HG(2004) Adaptive navigation function of the kindergarten toddler pool. Korea National University of Education Curriculum Research Institute (ed.), subject to improve the quality of education teaching and learning materials development and utilization Develop plans. 3-13

Field T, Grizzle N, Scafidi F, Abrams S, Richardson S (1996) Massage therapy for infants of depressed mothers. Infant Behavior Develop 19, 109-114

Fletcher AC, Newsome DW, Nickerson PF, Bazley $\mathrm{R}(2001)$ Social network closure and child adjustment. Merrill-Palmer Quarterly 47, 500-531

Gu BG(2002) Treatment of autistic children education, Committed: Seoul

Gwak GJ(2005) Seoul, South Korea infant development study. Hakjisa: Seoul

Jeong $\mathrm{ON}(2000)$ Education of children with disabilities cope with emotional behavior and outlook. Autistic infants attachment formation and study of physical activity play. Korea Institute of emotional learning disabilities educational materials 8th Conference

Jo BH(2006) Child development (revised). Educational Science: Seoul

Jo HJ(2004) Social and emotional development of children on family characteristics, child care experiences, and temperament variables analyzed, Ph.D. dissertation, Ewha Woman University

Kim GJ(2004) Status of infants and preschool peer relationships and adaptation. Master's Thesis, Korea National University of Education Graduate School

Kim HW(2009) Teacher-child interactions and the relationship between the type and the infant's play. Konkuk University, Graduate School of Education Master's Thesis

Kim JE(2003) 5 year olds and kindergarten adjustment of the relationship between emotional intelligence. Korea National University of Education Graduate School of Education Master's Thesis 
Kim NY, Shin Yl(2001) Perceived by teachers and preschool children's temperament and the relationship between adaptation. Yonsei Educ Sci 49, 145-161

Lee $\mathrm{SH}(2000)$ Cesarean section, postpartum massage program effects on maternal stress response, Kyungpook National University, Ph.D. dissertation

Morrow CJ, Field TM, Scafidi FA, Roberts LE, Eisen L(1991) Differential effects of massage and heelstick procedures on transcutaneous oxygen tension in preterm infants. Infant Behavior Develop 14, 397-414

Oh JE(2001) Infant and nursery stability of the attachment relationship between initial adaptation, Yonsei University Graduate School of Education, Master Thesis

Perry KE, Weinstein RS(1998) The social context of early schooling and children's school adjustment. Educ Psychol 33(4), 177-194

Pro Reader(2011) Baby massage \& yoga international professional association leaders. Seoul : Inclination Media

Schanberg S, Field T(1987) Sensory deprivation stress and supplemental stimulation in the pup and preterm human neonate. Child Develop 58, 1431-1447
Song HJ(2007) 2 year old child's temperament and nursery relationship between initial adaptation and play. Sungshin Woman's University Graduate School of Education, Master's Thesis

Soo HS(2000) Symptoms of cancer patients hospitalized for pain relief therapy. Foot Massager Health Res Center issue Web Health Res 3(11), 2-6

Washington Post(2002) Mom hands helping hand. 2002.7.29

Yang SG(2010) Mother's separation anxiety, the teacher-child relationship Sevan 1.2 million impact on the child's nursery adaptation: child care facilities, national and public child care facilities, child care facilities using private Catholic University, mainly infants, Master's Thesis, Catholic University

Yi YR(2012) Growing baby massage yamada miss toshi strong writing, Leescom: Seoul 